\title{
The Use of Phenanthraquinone Monophenyl Thiosemicarbazone for Preconcentration, Ion Flotation and Spectrometric Determination of Zinc(II) in Human Biofluids and Pharmaceutical Samples
}

\author{
Magda Ali Akl \\ Department of Analytical Chemistry, Faculty of Science, Mansoura University, 35566, P.O. Box 70, Mansoura, Egypt \\ E-mail: magdaakl_59@hotmail.com \\ Received March 4, 2006
}

\begin{abstract}
A rapid flotation methodology for zinc(II) separation and enrichment from human biofluids is established. At pH 6.0 and ambient temperature, using oleic acid (HOL) as a foaming reagent, zinc(II) was separated with phenanthraquinone monophenyl thiosemicarbazone (PPT) as a new flotation collector for $\mathrm{Zn}$ (II). The floated red colored $1: 2 \mathrm{Zn}(\mathrm{II})-\mathrm{PPT}$ complex was measured spectrophotometrically at $526 \mathrm{~nm}$ with a molar absorptivity of $1.83 \times 10^{5} \mathrm{~L} \mathrm{~mol} \mathrm{~L}^{-1} \mathrm{~cm}^{-1}$. Beer's law was obeyed over a concentration range $0.05-1.0 \mathrm{mg} \mathrm{L}^{-1}$ in the aqueous as well as in the scum layers. The proposed preconcentration flotation methodology was applied to determine $\mathrm{Zn}$ (II) in human biofluids. Application was, also, extended to determine Zn(II) in pharmaceutical samples and natural water samples spiked with known amounts of $\mathrm{Zn}$ (II) with a preconcentration factor of 100 and a detection limit of $10 \mathrm{ng} \mathrm{mL}^{-1}$. The method was verified by comparison of the spectrophotometric results with flame atomic absorption spectrometric (AAS) measurements. Moreover a postulation for the mechanism of flotation is proposed.
\end{abstract}

Key Words : Ion flotation, Preconcentration, Zn(II), Biofluids, Drugs

\section{Introduction}

Zinc is an essential microelement for growth, reproduction and development of living mammals. In addition to its role in catalysis and gene expression, zinc stabilizes the structure of proteins and nucleic acids, preserves the integrity of subcellular organelles, participates in transport and has an important role in viral and immune phenomena. ${ }^{1}$ Zinc deficiency in human is clearly associated with certain clinical syndromes and possibly implicated in others. Growth retardation, anorexia, lethargy, hypogonadism, alopecia, confusion, apathy and delayed wound healing are variable manifestations of zinc deficiency in human. ${ }^{1}$

Recently, the interests for health-related and environmental sciences are widely and rapidly increased and the information about trace heavy metals is also becoming more important. Therefore, development of accurate determinations methods for them is necessary to fit such requirements. As a result, various types of powerful and elegant instruments have been developed up to present time for a qualitative and quantitative analysis of materials in view of composition as well as structure. Besides, various instrumental techniques have been extensively developed to improve the sensitivity, precision, selectivity and efficiency of analytical methods; but the combination of an appropriate preconcentration technique with these methods remains unsettled in the field of trace inorganic analysis to achieve successful analyses in many kinds of samples. ${ }^{2}$

The solvent extraction, ${ }^{3-5}$ adsorption, ion exchange, ${ }^{6,7}$ and coprecipitation $^{8}$ are commonly used as preconcentration techniques for the spectrometric determination of trace heavy elements. However, these methods need relatively long time and troublesome operation for a large volume of sample.

A flotation technique, ${ }^{9-30}$ on the other hand, is rapid and convenient compared to such preconcentration techniques and can be performed with an unskillful technique. This method is also able to concentrate many elements from a large sample volume of several liters to less than $10 \mathrm{~mL}$, simultaneously.

The flotation technique is defined as a separation procedure by which various substances in a solution are selectively floated to the surface with the aid of tiny gas bubbles. The flotation technique can be classified into precipitate flotation and ion flotation. ${ }^{30}$ In ion flotation technique, the desired trace ions in an aqueous solution are converted into hydrophobic species by adding complexing agents and/or surfactants, floated with the aid of numerous bubbles and concentrated in a scum or copious foam layer on the solution surface. ${ }^{30}$

The aim of the present study is to introduce phenanthraquinone monophenyl thiosemicarbazone (PPT) as a new reagent for the flotation of $\mathrm{Zn}$ (II) in media of diverse origin. In this study, trace amounts of $\mathrm{Zn}$ (II) were converted into Zn-PPT complex by adding PPT and then the complex in the aqueous sample solution was rendered hydrophobic by the addition of oleic acid (HOL) surfactant and floated to the scum layer by vigorous shaking. The floated substance was collected and the $\mathrm{Zn}$ (II) concentration was determined spectrophotometrically and verified by flame atomic absorption spectrometry(AAS). The various experimental variables such as $\mathrm{pH}$, temperature, amount of PPT, type and amount of 
surfactant, and so on, were optimized in the flotation procedure. Finally, this procedure was applied for the determination of $\mathrm{Zn}(\mathrm{II})$ in human biofluids, pharmaceutical samples and in natural water samples spiked with known amounts of $\mathrm{Zn}$ (II).

\section{Experimental Section}

\section{Chemicals and solutions.}

Synthesis of phenanthraquinone monophenyl thiosemicarbazone (PPT), ${ }^{31}$ (Scheme 1): A hot solution of 4phenylthiosemicarbazide $(0.334 \mathrm{~g}, 2 \mathrm{mmol}$ in ethanol) was added to ( $0.416 \mathrm{~g}, 2 \mathrm{mmol})$ 9,10-phenanthraquinone dissolved in the least amount of glacial acetic acid. The resulting solution was boiled under reflux for $1 \mathrm{~h}$. The PPT crystals were filtered off, washed with ethanol, recrystallized from absolute ethanol and finally dried in a vacuum desiccators over anhydrous $\mathrm{CaCl}_{2}$.

The foaming reagents tested for the procedure were sodium palmitate $(\mathrm{NaPL})$, sodium stearate $(\mathrm{NaST})$, oleic acid (HOL), cetyltrimethylammonium bromide (CTAB) and Tween 80 . Tween 80 was made as $0.5 \%$ aqueous, while $\mathrm{NaPL}, \mathrm{NaST}$ as $99.7 \%$ propanolic solution. CTAB was used as $95 \%$ ethanolic solution. An oleic acid (HOL) stock solution $\left(6.36 \times 10^{-2} \mathrm{~mol} \mathrm{~L}^{-1}\right)$ was prepared by dispersing 20 $\mathrm{mL}$ of HOL food grade $(d 0.895)$, in $1 \mathrm{~L}$ kerosene.

Zinc stock solution $\left(1000 \mathrm{mg} \mathrm{L}^{-1}\right)$ was prepared by dissolving $1.000 \mathrm{~g}$ of zinc metal in $15 \mathrm{~mL}$ of $1: 1 \mathrm{HCl}$ and dilute to $1 \mathrm{~L}$ with doubly distilled water (DDW). All other reagents used were of analytical reagent grade. Doubly distilled water (DDW) was used throughout this work.

To check the accuracy and precision of the proposed flotation procedure a certified reference material was analyzed viz.: stream sediment SARM 52 prepared by MINTEX (Ranburg, Republic of South Africa).

Pharmaceutical samples like Mineravit (E.I.P.I. Co.), Megavit Zinc (Amriya Pharm. Ind.) and Vitaplus Zinc (CID) were selected for the analysis of $\mathrm{Zn}(\mathrm{II})$.

Instrumentation: Two types of flotation cells were used throughout this study as it has already been described. ${ }^{20-28}$

The concentration of $\mathrm{Zn}$ (II) was determined using a Unicam UV $2100 \mathrm{UV} / \mathrm{vis}$ spectrometer and was confirmed by flame AAS measurements at $214 \mathrm{~nm}$ with a Perkin-Elmer 2380 atomic absorption spectrometer (USA) with a Pye Unicam (England) hollow cathode lamp and a conventional $10 \mathrm{~cm}$ slit burner head for air acetylene flame.

Adjustment of $\mathrm{pH}$ of the sample solutions was carried out in the range of 1-10 using $0.1 \mathrm{~mol} \mathrm{~L}^{-1} \mathrm{HCl}$ and/or 0.5<smiles>O=C1/C(=N\NC(=S)Nc2ccccc2)c2ccccc2-c2ccccc21</smiles>

Scheme 1 mol L ${ }^{-1} \mathrm{NaOH}$. To monitor the $\mathrm{pH}$ of the media, a Hanna Instruments 8515 digital $\mathrm{pH}$ meter was used.

Analytical procedures.

Flotation-separation of $\mathbf{Z n}(\mathrm{II})$ : In an Erlenmeyer flask, $2.0 \mathrm{~mL}$ of $1 \times 10^{-3} \mathrm{~mol} \mathrm{~L}^{-1}$ PPT solution was added to an aliquot containing $2 \times 10^{-5} \mathrm{~mol} \mathrm{~L}^{-1} \mathrm{Zn}$ (II) and $1 \mathrm{~mL}$ of 0.05 mol L ${ }^{-1} \mathrm{Na}_{2} \mathrm{~S}_{2} \mathrm{O}_{3}$; the $\mathrm{pH}$ was adjusted to 6.0. The mixture was shaken well for few seconds to allow complete complexation of PPT with $\mathrm{Zn}(\mathrm{II})$ ions. A red color of $\mathrm{Zn}$ PPT complex developed instantaneously. All contents were quantitatively transferred into flotation cell and its volume was adjusted to $10 \mathrm{~mL}$. Then, $3 \mathrm{~mL}$ of $2 \times 10^{-4} \mathrm{~mol} \mathrm{~L}^{-1} \mathrm{HOL}$ was added. The flotation cell was shaken upside down for 2 min by hand. Vigorous shaking of the flotation cell in the presence of a surfactant (HOL) creates bubbles in the solution which enhance the floatability of Zn-PPT complex. At equilibrium, a foamy layer was obtained and the aqueous solution in the cell became completely cleared of the colored complex. The processed aqueous phase was run off through the bottom of the cell. The scum layer, in which $\mathrm{Zn}$ (II) was concentrated, was taken into a small vial to determine $\mathrm{Zn}$ (II) by spectrophotometric and AAS measurements.

Spectral detection: A suitable volume of the scum layer was transferred to a 2-cm quartz cell and the absorbance was measured at $526 \mathrm{~nm}$ against a reagent blank to determine the concentration of $\mathrm{Zn}$ (II).

To determine the concentration of $\mathrm{Zn}(\mathrm{II})$ by flame AAS, the scum layer was stripped with $2 \mathrm{~mL}$ of $(1: 1) \mathrm{HNO}_{3}$ and the resultant clear solution was aspirated directly to the flame to measure $\mathrm{Zn}$ (II) concentration at $214.0 \mathrm{~nm}$.

The flotation efficiency (F, \%) was calculated from the relation

$$
\mathrm{F}=\left(\mathrm{C}_{\mathrm{s}} / \mathrm{C}_{\mathrm{i}}\right) \times 100
$$

Here $\mathrm{C}_{\mathrm{i}}$ and $\mathrm{C}_{\mathrm{s}}$ are the concentration of $\mathrm{Zn}$ (II) in the initial aqueous and scum layers, respectively.

Sample analysis.

Analysis of water samples (Recovery test): Tap water, Nile River water and sea water samples were collected from the city of Mansoura (Mansoura is an agro-industrial area in the Nile Delta, Egypt) and its neighborhood. Samples were filtered using a $0.45 \mu \mathrm{m}$ pore size membrane filter to remove any suspended particulate matter and immediately treated with few milliliters of conc. $\mathrm{HNO}_{3}$ to prevent possible hydrolytic precipitation of some mineral salts.

Different concentrations of $\mathrm{Zn}$ (II) viz.: $0.5 \mu \mathrm{g} \mathrm{mL} \mathrm{m}^{-1}$ and 1 $\mu \mathrm{g} \mathrm{mL}$, were introduced to $20 \mathrm{~mL}$ aliquots of water samples, and $2 \mathrm{~mL}$ of $2.5 \times 10^{-3} \mathrm{~mol} \mathrm{~L}^{-1}$ PPT were added. The same previous steps of flotation, metal stripping and spectrophotometry were carried out and the recovery percentages were calculated.

Analysis of human biofluids: Blood serum and urine samples were collected from 10 healthy children and from 10 cases of Nephrotic Syndrome (NS). Serum and urine samples ( $5 \mathrm{~mL}$ each) were acidified using $2 \mathrm{~mL}$ of $\mathrm{HClO}_{4}$ : $\mathrm{HNO}_{3}(1: 3)$ mixture, boiled to near dryness, dissolved in DDW and brought to $50 \mathrm{~mL}$ in a calibrated flask. Into 
flotation cell (a), $2 \mathrm{~mL}$ of the cold solution of the pretreated sample was introduced and the flotation process was completed as before.

Analysis of pharmaceutical samples: The selected zinc containing drug samples were brought into solution by adopting the following procedure. Each sample was treated separately with concentrated nitric acid on a hot-plate, at a low temperature, to avoid violent spurting. The residue of each sample was cooled and again $1: 1$ nitric acid is added. The temperature of the hot-plate was gradually increased to $300{ }^{\circ} \mathrm{C}$. The residue obtained was dissolved in nitric acid $(1$ : 1) and was slowly heated for $2 \mathrm{~h}$ to procure a dry mass. Finally, the residue was dissolved in a minimum amount of DDW. The sample solution was quantitatively transferred into a $100 \mathrm{~mL}$ volumetric flask and then made to the mark with DDW and analyzed for $\mathrm{Zn}(\mathrm{II})$, by using the recommended general procedure.

\section{Results and Discussion}

PPT and its metal complexes. If we consider the structure of the chromogen PPT, Scheme 1, and its metal complexes, Scheme 2 and 3, it is apparent that the chromogen molecule contains a number of reactive sites involving $-\mathrm{N}$ $\mathrm{NH}, \mathrm{C}=\mathrm{S}$ and $\mathrm{C}-\mathrm{NH}$ in association with the condensed benzenoid rings, which are known to chelate strongly with a whole raft of elements in Groups $1 b, 2 b, 3 b, 4 b, 5 b$ and $6 b$ of Periods 4, 5 and 6 of the Periodic Classification, with chelation through the $\mathrm{N}, \mathrm{S}$ and/or $\mathrm{O}$ atoms.

PPT can react with several ions as a bidentate ligand (Scheme 2), in the thione form coordinating via $\mathrm{N}=\mathrm{N}$ and the enolic carbenyl oxygen with the displacement of hydrogen atom from the latter group to form hydrophobic complexes. ${ }^{22}$ PPT can also act as a tridentate ligand (Scheme 3 ) in the enolthione form coordinating via the $\mathrm{C}=\mathrm{S}, \mathrm{N}=\mathrm{N}$ and the enolic carbonyl $\mathrm{OH}$ with the displacement of hydrogen atom from the latter group. ${ }^{23}$

In general, PPT has the ability to form a stable complex of $1: 2$ molar ratio with most divalent metal ions. However, Khalifa et al., ${ }^{23}$ showed that two kinds of complexes could be formed with a copper ion: $\mathrm{Cu}$ : PPT in the aqueous solution of $\mathrm{pH} 3.0-3.5$ and the $\mathrm{Cu}(\mathrm{PPT})_{2}$ at $\mathrm{pH} \geq 6.5$.

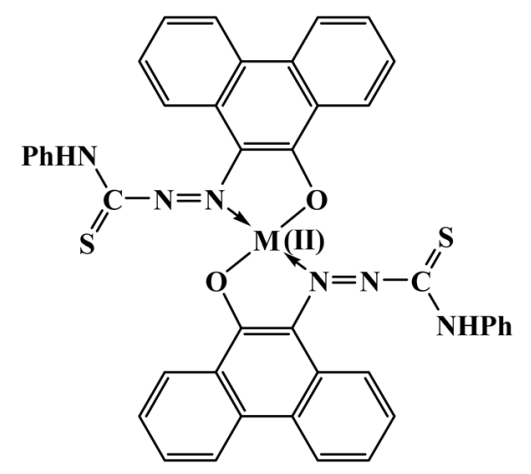

Scheme 2

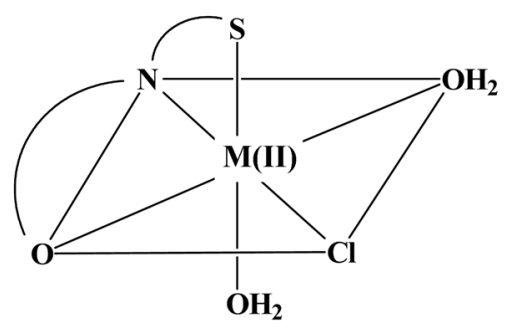

Scheme 3. PPT as a tridentate ligand.

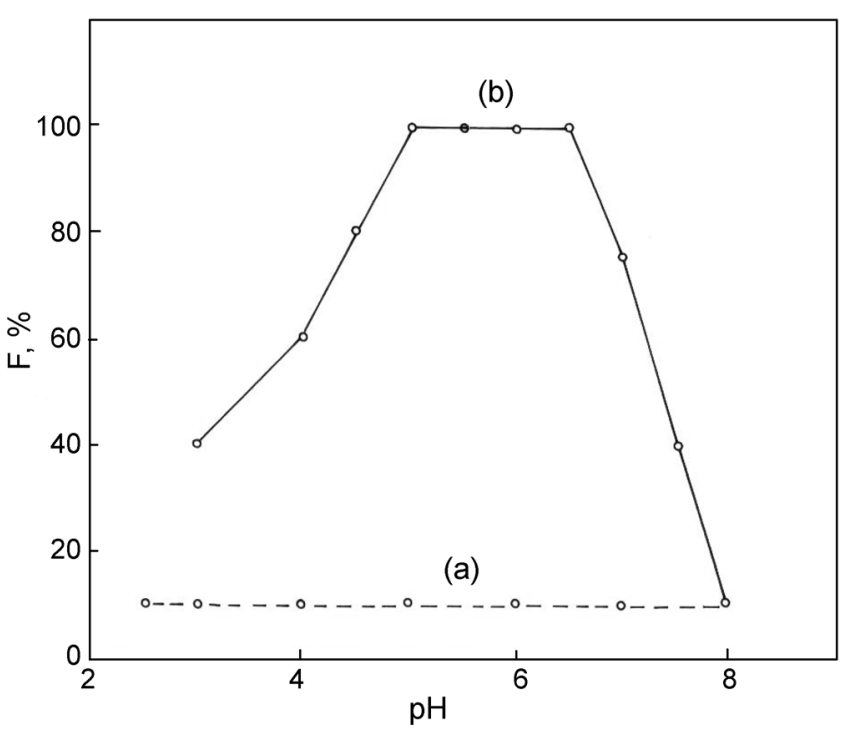

Figure 1. Influence of $\mathrm{pH}$ values on the flotation efficiency (F,\%) of $\mathrm{Zn}$ (II): (a) in the absence of PPT and (b) $2.5 \times 10^{-3} \mathrm{~mol} \mathrm{~L}^{-1}$ PPT and $2 \times 10^{-4} \mathrm{~mol} \mathrm{~L}^{-1} \mathrm{HOL}$.

\section{Influence of experimental variables.}

Influence of pH: The $\mathrm{pH}$ of solution is a very important factor for metal chelate formation and for the flotation process. Therefore, the effect of the $\mathrm{pH}$ on the flotation of $\mathrm{Zn}$-PPT chelate was studied in the $\mathrm{pH}$ values ranging from 2.0 to 10. The results are shown in Figure 1. In the absence of PPT (graph a) the flotation efficiency of Zn(II) is very low over the $\mathrm{pH}$ range tested. Maximum flotation efficiency (>95\%) was obtained for $\mathrm{Zn}$ with PPT over $\mathrm{pH}$ values ranging from 4.5 to 7.5 . The role of the reagent PPT is quite evident from comparison of graphs (a) and (b). The PPT reagent forms $\mathrm{Zn}$-PPT complex with zinc ions rendering them more hydrophobic and easily separated from the solution bulk. At higher $\mathrm{pH}$ values the decrease in the flotation efficiency may be attributed to the formation of a white emulsion and due to the formation of excessive foams of sodium oleate. This will hinder the reaction to complete. Additionally, zinc can form hydroxide precipitates in a strongly basic solution.

Selection of a suitable surfactant: The addition of foaming agents is very advantageous because they transform the hydrophilic surface of the species floating in hydrophobic and so they facilitate the separation of the formed metal chelate from the aqueous phase to the scum layer.

To select properly an appropriate surfactant for the pro- 
Table 1. Applicability of different foaming reagents for ion flotation of zinc using PPT as a complexing agent $(\mathrm{Zn}(\mathrm{II})=10 \mu \mathrm{g}$, $\mathrm{PPT}=2 \times 10^{3} \mathrm{~mol} \mathrm{~L}^{-1}, \mathrm{Ic}=0.01 \mathrm{~mol} \mathrm{~L}^{-1}, \mathrm{pH}=6.0$ at $25^{\circ} \mathrm{C}$

\begin{tabular}{lc}
\hline Surfactant & Recovery, R\% \\
\hline 1. Non ionic & Foam, no flotation \\
- Tween 80 & \\
2. Cationic & Foam, no flotation \\
- CTAB & \\
3. Anionic & \\
i. Single & 80 \\
- NaST & 100 \\
- HOL & 90 \\
- NaPL & \\
ii. In pairs & 85 \\
- NaST + NaPL & 80 \\
- HOL + NaPL & \\
\hline
\end{tabular}

cedure, several foaming reagents were tested at $\mathrm{pH} 6.0$ using $2.5 \times 10^{-3} \mathrm{~mol} \mathrm{~L}^{-1} \mathrm{PPT}$ and $5 \mathrm{~mL}$ of surfactant solution (with specified concentration for each one).

It was found that the cationic surfactant $(\mathrm{CTAB})$ and the non ionic tenside (Tween 80 ) were inadequate. They frothed well at $\mathrm{pH} 6.0$, but they didn't help to separate the Zn-PPT complex from the processed solution. The surface of the formed $\mathrm{Zn}$-PPT complex particles might be of the same charge as that of the CTAB cationic surfactant causing their ineffectiveness compared to the anionic surfactants used.

Among the anionic surfactants singly tested (NaPL, NaST and HOL) and in pairs (NaST/NaPL and HOL/NaPL), HOL was the most helpful (Table 1), achieving the highest recovery value of $\sim 100 \%$. The results obtained by the pairs $\mathrm{NaST} / \mathrm{NaPL}$ and HOL/NaPL were also satisfactory, but this combination of agents formed too much scum, which was very difficult to decompose by acid. When HOL was used as a single agent the stripping of $\mathrm{Zn}$ from the scum layer was easier and faster. Therefore, HOL was selected for the procedure.

Influence of oleic acid (HOL) concentration: The concentration of HOL is an important parameter; up to a certain limit the flotation efficiency $(F, \%)$ increases as the concentration of HOL increases. Figure 2, shows that the flotation efficiency of $\mathrm{Zn}$ (II) gradually increases as the concentration of HOL increases reaching $\sim 100 \%$ over a wide range of HOL concentration $\left(2 \times 10^{-5}-8 \times 10^{-4} \mathrm{~mol} \mathrm{~L}^{-1}\right)$. At a higher HOL concentration the surfactant molecules will gather together to form a microball called a micelle. ${ }^{32}$ Micelles compete with the colligend molecule ( $\mathrm{Zn}$-PPT complex) and since they stay in solution, they reduce the effectiveness of separation. Also, the concentration of surfactant changes the bubble size with the size getting smaller as the surfactant increases. This makes creamier foam. ${ }^{32}$ A suitable concentration of HOL $\left(2 \times 10^{-4} \mathrm{~mol} \mathrm{~L}^{-1}\right)$ was used throughout this work.

Influence of PPT concentration: A sufficient amount of the ligand is needed for the complex formation of the trace metal ions under other optimum conditions. The flotation

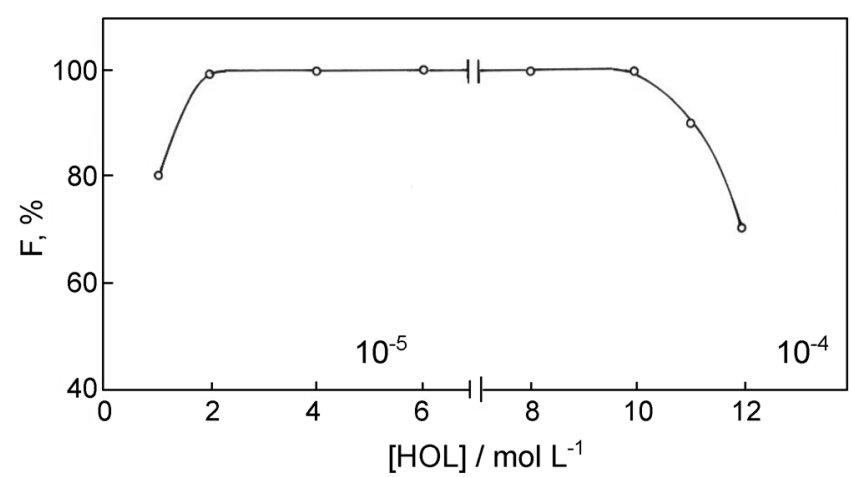

Figure 2. Influence of oleic acid (HOL) concentration on the flotation efficiency $(\mathrm{F}, \%)$ of $\mathrm{Zn}(\mathrm{II})$.

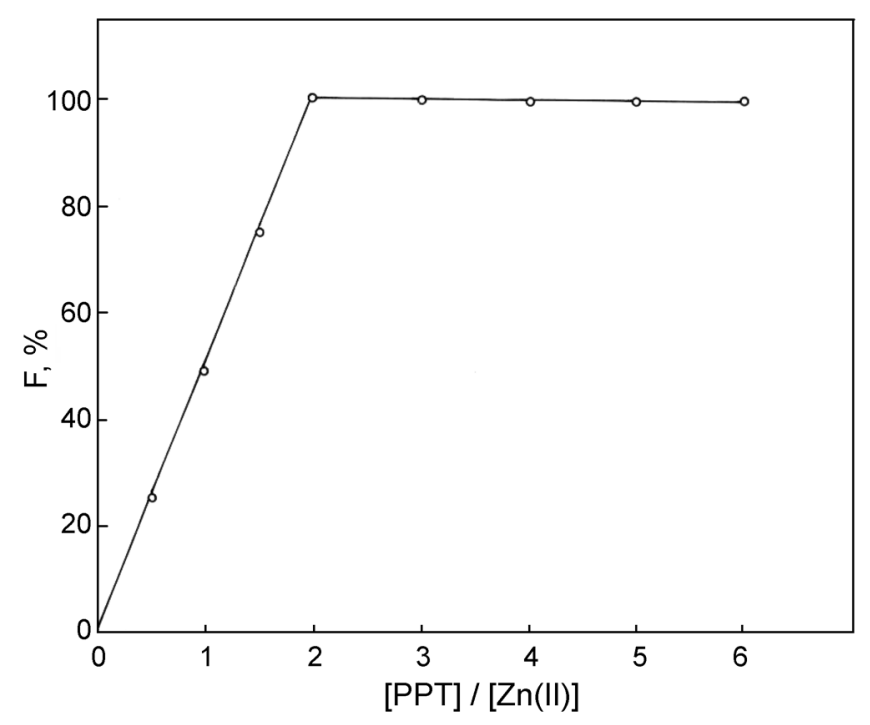

Figure 3. Influence of the phenanthraquinone monophenyl thiosemi-carbazone reagent (PPT) concentration.

efficiency (F, \%) was measured in aqueous solution of various PPT $(n=5)$ concentrations; the results are shown in Figure 3 as a function of $[\mathrm{PPT}]_{(\mathrm{aq}, \mathrm{i})} / \mathrm{Zn}(\mathrm{II})_{(\mathrm{aq}, \mathrm{i})}$. The figure clearly shows that (1) the flotation of $\mathrm{Zn}$ (II) becomes possible in the presence of PPT; (2) the value for (F, \%) increases with an increase in the PPT concentration and reaches $\sim 100 \%$ at 2.0 showing clear abrupt points. Based on these findings, it was estimated that $\mathrm{Zn}$ (II) was floated as $\mathrm{Zn}$ $:$ PPT $=1: 2(n=5)$ complex. Figure 3 , also shows that increasing the concentration of PPT doesn't affect the flotation process. A concentration of $2.5 \times 10^{-3} \mathrm{~mol} \mathrm{~L}^{-1} \mathrm{PPT}$ was chosen to account for other floatable species in real samples.

Influence of temperature: Maximum flotation efficiency was achieved at temperature values ranging from 20 to 45 ${ }^{\circ} \mathrm{C}$. The proposed flotation procedure was performed at room temperature i.e. $\sim 25{ }^{\circ} \mathrm{C}$.

Influence of shaking time: Figure 4, shows the influence of shaking time of the original solutions (i.e. before flotation) on the flotation efficiency of $\mathrm{Zn}$ (II) at $\mathrm{pH} 6.0$ in the presence of $2.5 \times 10^{-3} \mathrm{~mol} \mathrm{~L}^{-1} \mathrm{PPT}$ and then adding $2 \times 10^{-4}$ mol L $\mathrm{L}^{-1} \mathrm{HOL}$ at room temperature. As it can be noticed, the 


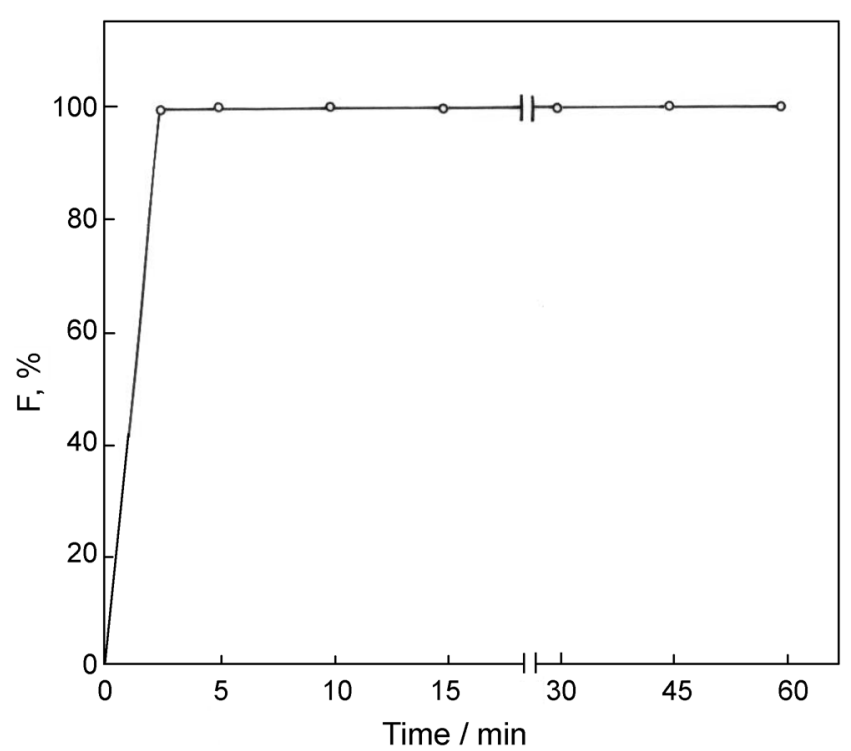

Figure 4. Influence of shaking time on the flotation efficiency $(\mathrm{F}, \%)$ of $\mathrm{Zn}(\mathrm{II})$ in the presence of $2.5 \times 10^{-3} \mathrm{~mol} \mathrm{~L}^{-1} \mathrm{PPT}$ and $2 \times$ $10^{-4} \mathrm{~mol} \mathrm{~L}^{-1} \mathrm{HOL}$.

flotation efficiency reaches its maximum $(\sim 100 \%)$ after about $2 \mathrm{~min}$ and remains constant. Proper shaking allowed the successful comlpexation of PPT and $\mathrm{Zn}$ (II) to form hydrophobic Zn-PPT complex that is easily floated by HOL. A shaking time of $3 \mathrm{~min}$ was used in the subsequent experiments.

Effect of ionic strength: The effect of the ionic strength $\left(I_{\mathrm{c}}\right)$ on $\mathrm{Zn}$ (II) floatability was studied by using different ionic strength adjusters. The results of this investigation are given in Table 2. The data proved that the flotation recoveries of zinc show only a slight variation over a wide concentration range of the ionic strength.

Influence of volume: A series of experiments was conducted to float different concentrations of $\mathrm{Zn}$ (II) from different aqueous volumes using suitable large flotation cells under the recommended conditions. The results obtained revealed that, up to $10 \mu \mathrm{g}$ of $\mathrm{Zn}$ (II) could be quantitatively separated from one liter into $10 \mathrm{~mL}$ of HOL with a preconcentration factor of 100 . Accordingly, the detection limit

Table 2. Dependence of the zinc flotation recoveries on the ionic strength (Ic) of the solution

\begin{tabular}{clc}
\hline Ionic strength (Ic), $\mathrm{mol} \mathrm{L}^{-1}$ & Adjuster & Recovery, \% \\
\hline 0.01 & $\mathrm{NaCl}$ & 100.0 \\
& $\mathrm{Na}_{2} \mathrm{SO}_{4}$ & 99.5 \\
& $\mathrm{MgCl}_{2}$ & 99.0 \\
& & \\
& $\mathrm{NaCl}$ & 99.5 \\
0.05 & $\mathrm{Na}_{2} \mathrm{SO}_{4}$ & 99.0 \\
& $\mathrm{MgCl}_{2}$ & 98.0 \\
& & \\
& & 99.6 \\
& $\mathrm{NaCl}^{*}$ & 98.5 \\
& $\mathrm{Na}_{2} \mathrm{SO}_{4}$ & 98.2 \\
& $\mathrm{MgCl}_{2}$ & \\
\hline
\end{tabular}

Table 3. Influence of foreign ions on the preconcentration and determination of $\mathrm{Zn}(\mathrm{II}), 0.2 \mu \mathrm{g}$. Tolerance error (5\%)

\begin{tabular}{ccc}
\hline Foreign ions & Concentration, $\mathrm{mg} \mathrm{L}^{-1}$ & Recovery, $\mathrm{R} \%$ \\
\hline $\mathrm{K}^{+}$ & $1 \times 10^{4}$ & 104 \\
$\mathrm{Na}^{+}$ & $1 \times 10^{4}$ & 103 \\
$\mathrm{Ca}^{2+}$ & $1 \times 10^{3}$ & 101 \\
$\mathrm{Mg}^{2+}$ & $1 \times 10^{3}$ & 96 \\
$\mathrm{Al}^{3+}$ & 10 & 99 \\
$\mathrm{Fe}^{3+}$ & $0.5^{b}$ & 99 \\
$\mathrm{Cd}^{2+}$ & $0.5^{a}$ & 99 \\
$\mathrm{Co}^{2+}$ & 0.5 & 98 \\
$\mathrm{Pd}^{2+}$ & 0.5 & 97 \\
$\mathrm{Hg}^{2+}$ & 0.5 & 99 \\
$\mathrm{Cu}^{2+}$ & 0.5 & 96 \\
$\mathrm{~Pb}^{2+}$ & 0.5 & 100 \\
$\mathrm{Ni}^{2+}$ & 0.5 & 99 \\
$\mathrm{Mn}^{2+}$ & 0.5 & 100
\end{tabular}

${ }^{a}$ After addition of $1 \mathrm{~mL}$ of $0.05 \mathrm{~mol} \mathrm{~L}^{-1} \mathrm{Na}_{2} \mathrm{~S}_{2} \mathrm{O}_{3},{ }^{b}$ After addition of 1 $\mathrm{mL} 0.05 \mathrm{~mol} \mathrm{~L}^{-1}$ ascorbic acid.

of such a separation procedure is $0.01 \mu \mathrm{g} \mathrm{mL}^{-1}$.

Interfering effects of various foreign ions: The effect of foreign metal ions on the flotation of $\mathrm{Zn}$ (II) with PPT has been studied in detail. Solutions containing $0.2 \mu \mathrm{g}$ of zinc(II) in $25 \mathrm{~mL}$ solution and various excesses of several cations and anions were prepared and the recommended flotation procedure was followed. The criterion for interference was fixed at a $5 \%$ variation of the average recovery percentage $(\mathrm{R}, \%)$, calculated for the established level of zinc The obtained results are shown in Table 3. The experimental data showed that $\mathrm{Na}(\mathrm{I}), \mathrm{K}(\mathrm{I}), \mathrm{Ca}(\mathrm{II}), \mathrm{Mg}(\mathrm{II})$, and $\mathrm{Al}(\mathrm{III})$ don't interfere in the recovery of $\mathrm{Zn}(\mathrm{II})$ whereas $\mathrm{Cd}(\mathrm{II}), \mathrm{Cu}(\mathrm{II})$, $\mathrm{Hg}(\mathrm{II}), \mathrm{Fe}(\mathrm{III})$ and $\mathrm{Pd}(\mathrm{II})$ have little interfering effects $(\sim 2 \%)$. All of these interferences were completely controlled by adding excess PPT $\left(2 \times 10^{-3} \mathrm{~mol} \mathrm{~L}^{-1}\right)$ and /or masking agents $\mathrm{In}$ this regard, $\mathrm{Na}_{2} \mathrm{~S}_{2} \mathrm{O}_{3}$ was used to suppress the interferences of $\mathrm{Cd}(\mathrm{II}), \mathrm{Pd}(\mathrm{II}), \mathrm{Hg}$ (II) and $\mathrm{Cu}(\mathrm{II})$. $\mathrm{Fe}(\mathrm{III})$ was reduced to $\mathrm{Fe}(\mathrm{II})$ by ascorbic acid before flotation of $\mathrm{Zn}$ (II). Cadmium forms analogous compound of the same color of $\mathrm{Zn}$-PPT complex, but it was found that upon using the method of simultaneous equation, ${ }^{33} 0.2 \mu \mathrm{g}$ of $\mathrm{Zn}$ (II) was successfully determined in the presence of $0.5 \mathrm{mg} \mathrm{L}^{-1}$ of $\mathrm{Cd}(\mathrm{II})$. Anions such as acetate, $\mathrm{Cl}^{-}, \mathrm{PO}_{3}{ }^{-}, \mathrm{ClO}_{4}^{-}, \mathrm{I}^{-}, \mathrm{NO}_{3}^{-}$, oxalate, citrate and tartarate do not interfere.

Moreover, the effects of the same studied foreign ions on the flame AAS determination of $\mathrm{Zn}$ (II), were investigated. No single anion or cation caused a variation in the response by more than $\pm 5 \%$. It is of great interest to note that the selected investigated elements (usually present as main element and traces in water and/or blood) have no deleterious effect on the analyte separation and determination under the recommended conditions.

\section{Characterization of Zn-PPT complex.}

Absorption spectra of PPT and Zn-PPT complexes: The absorption spectra of the PPT, Zn-PPT complex in the aqueous and in the scum layer, are shown in Figure 5. PPT has two characteristic maxima at $410 \mathrm{~nm}$ and $450 \mathrm{~nm}$ (graph 


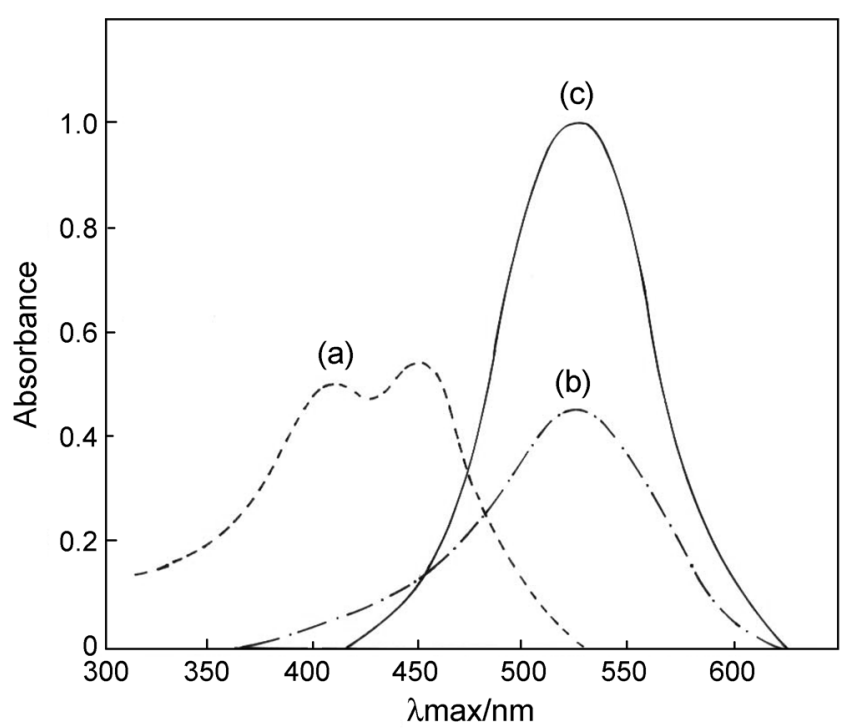

Figure 5. Absorption spectra of (a) PPT in aqueous acetone solution, (b) Zn-PPT complex in aqueous solution and (c) Zn-PPT complex in oleic acid (HOL) layer.

a). The presence of these two maxima is attributed to the keto enol and thioenol equilibrium (Scheme 4).

The absorption spectrum of $\mathrm{Zn}(\mathrm{II})-\mathrm{PPT}$ complex is completely different from that of PPT. It is observed that (i) the $\lambda_{\max }$ of $\mathrm{Zn}$-PPT exhibits a red shift of $76 \mathrm{~nm}$ from that of PPT (curve b); (ii) only a single Zn-PPT chelate is formed in the aqueous and in the scum layer; having a maximum absorbance at $526 \mathrm{~nm}$ and (iii) the absorbance of Zn-PPT in the HOL layer (curve c) is much more than that of Zn-PPT in the aqueous solution (curve b). This proves that the species are highly concentrated in the HOL layer.

PPT is yellowish in color. Chelated with $\mathrm{Zn}(\mathrm{II})$, PPT changes its color drastically to red color in accordance with the assumption that zinc ions are bonded to PPT by complex formation.

Stability of Zn-PPT chromogenic system: The absorbance of the $\mathrm{Zn}$-PPT complex reaches a maximum value instantly at room temperature and remains constant for $48 \mathrm{~h}$ at least. The stability constant was calculated to be $1.26 \times$ $10^{11}$.

Composition of the floated Zn-PPT complex. The stoichiometry of the Zn-PPT complex was studied under the established experimental conditions by the continuous variation ratio. The results obtained indicated that the composition of the complex was $1: 2\left(\mathrm{Zn}^{2+}:\right.$ PPT), Scheme 2 .
Analytical figures of merit. The effective molar absorption was calculated from the data obtained by the measurements of the organic phase absorbance as the condition of flotation was completed. The calibration graph obtained was a straight line passing through the origin over the concentration range mentioned above. The effective molar absorption coefficient $(\varepsilon)$ at 1 max $526 \mathrm{~nm}$ was $1.83 \times 10^{5} \mathrm{~L} \mathrm{~mol}^{-1}$ $\mathrm{cm}^{-1}$. The Zn-PPT complex obeys Beer's law from 0.05 to 1.0 $\mathrm{mg} \mathrm{L}^{-1}$ with an optimum range.

In order to validate the $\mathrm{Zn}$ (II) flotation procedure, the proposed method was applied to a certified reference material viz. stream sediment SARM 52 prepared by MINTEX (Ranburg, Republic of South Africa); certified zinc concentration was $1.32 \mathrm{ppm}$. Analytical recoveries were also determined. The average content found $(n=5)$ in the reference material was $1.28 \mathrm{ppm}$ with a precision as relative standard deviation, RSD, up to $5.0 \%$. The average analytical recovery $(n=5)$ obtained was about $98.5 \%$.

Comparison between PPT and other principal reagents for zinc determination. The proposed PPT reagent can be compared to some common previously reported reagents: dithizone, pyridyl azonaphthol (PAN) pyridylazoresorcinol $(\mathrm{PAR})^{34-36}$ and $\mathrm{TAN}^{37}$ reagents. In the dithizonemethod, the molar absorbitivity of zinc dithizonate in $\mathrm{ClCl}_{4}$ solution (at $\lambda_{\max }=538 \mathrm{~nm}$ ) is $9.26 \times 10^{4} \mathrm{~L} \mathrm{~mol}^{-1} \mathrm{~cm}^{-1}$, zinc is extracted in a double batch step and the extraction process is relatively slow. In the PAN method, the molar absorptivity of the chloroform solution of the zinc-PAN complex is $5.2 \times 10^{4} \mathrm{~L}$ $\mathrm{mol}^{-1} \mathrm{~cm}^{-1}$ at $\lambda_{\max }=560 \mathrm{~nm}$ ), the reagent absorbs little at the $\lambda_{\max }$ of the zinc complex. On the other hand, PAR allowed zinc to be determined with, a sensitivity similar to that for the PAN method. TAN was also used to extract $\mathrm{Zn}$ (II) into chloroform with a molar absorpitivity of $5.0 \times 10^{4} \mathrm{~L} \mathrm{~mol}^{-1}$ $\mathrm{cm}^{-1}$ at $\lambda_{\max }=581 \mathrm{~nm}$. In the present flotation methodology, the molar absorptivity of zinc(II)-PPT complex in the scum layer is $1.83 \times 10^{5} \mathrm{~L} \mathrm{~mol}^{-1} \mathrm{~cm}^{-1}$ (at $\lambda_{\max }=526 \mathrm{~nm}$ ), zinc is separated in a single batch, the reagent PPT does not absorb at the $\lambda_{\max }$ of zinc-PPT complex, the flotation process is rapid ( $<10 \mathrm{~min})$ and the scum layer can easily be measured spectrphotopmetrically or aspirated directly into the flame for AAS determination after elution. The hazardous effects of chloroform are completely avoided.

On the other hand, there are different reports for $\mathrm{Zn}$ (II) separation by colloid precipitate flotation ${ }^{9-13}$ or by ion flotation. ${ }^{14-17}$ In these reports $\mathrm{Zn}$ (II) was separated using different reagents such as aluminium hydroxide, ${ }^{9}$ hydrated iron hydroxide $\left(\mathrm{Fe}_{2} \mathrm{O}_{2} \mathrm{xH}_{2} \mathrm{O}\right),{ }^{10}$ iron(III)tetramthylene-dithio-<smiles>Oc1c(N=NC(=S)Nc2ccccc2)c2ccccc2c2ccccc12</smiles>

II

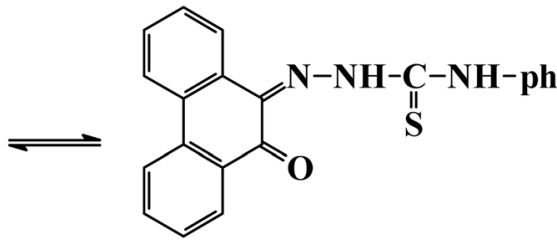

I

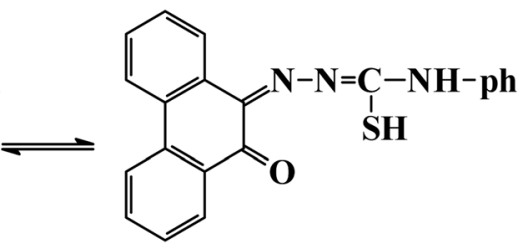

III

Scheme 4. Reaction equilibrium. 
carbamate $\left[\mathrm{Fe}(\mathrm{TMDTC})_{3}\right],{ }^{11}$ ferric hydroxide and aluminum hydroxide, cobalt(hexamethylenedithiocarbamate) [Co$\left.(\mathrm{HMDTC})_{3}\right],{ }^{12}$ iron(hexamethylenedithiocarbamate) [Fe(HMDTC) $\left.)_{3}\right],{ }^{13}$ 1-Naphthoic acid ${ }^{15}$ and 1,10-Phenanthroline. ${ }^{16}$ The figures of merits (detection limits, precision and recovery percentage) of the proposed ion flotation procedure are in a good comparison with those of previously reported reagents. Moreover, the color of Zn-PPT complex formed remains stable for long time which facilitates the simple measurements by the very simple spectrophotometry.

Mechanism of flotation. In studies concerning separation via flotation, the role of surfactant is very important. The nature of the interaction between oleic acid surfactant and the complex formed (Zn-PPT) must be studied to approach the actual mechanism of flotation. The proposed mechanism may proceed through: i) a physical interaction; ii) by forming a hydrogen bond between the hydrophilic part of HOL and the active sites in the ligand complex or iii) by an interaction between oleic acid and the complex, formed in solution through a coordinate bond forming a self-floatable (Zn-PPT-HOL) species. In all cases, the hydrophobic part of the surfactant attaches to air bubbles and floats separating the analyte-containing species.

In the present investigation, the mechanism of flotation is proposed to be physical in nature. This suggestion has been confirmed based on the following observations and experimental data: 1) The floated species has the same colour (red) as that obtained in the aqueous solution (especially in high reactants concentrations). 2) Raising the temperature above $45^{\circ} \mathrm{C}$ causes a marked decrease in the flotation efficiency of $\mathrm{Zn}$ (II). This may be attributed to the weak bonding between the oleic acid and the Zn(II)-PPT complex that is easily destroyed upon heating.

\section{Analytical application}

Determination of zinc in human biofluids. The determination of the total zinc level in human serum and urine samples was carried out by spectrophotometry and AAS after the flotation preconcentration was carried out. The serum and urine samples were collected from a healthy child (among healthy control group). The analytical results are summarized in Table 4, together with the relative standard deviations (RSDs) of the observed values estimated from three replicate analyses. In Table 4, the analytical results for
Table 4. Analytical results of total zinc in human blood serum and urine samples

\begin{tabular}{|c|c|c|c|c|}
\hline \multirow[b]{2}{*}{ Sample } & \multicolumn{2}{|c|}{ Intra-day assay $^{a}$} & \multicolumn{2}{|c|}{ Inter- day assay $^{b}$} \\
\hline & $\begin{array}{c}\text { Observed } \\
\text { value }^{c}\end{array}$ & $\begin{array}{c}\mathrm{RSD}^{d} \\
(\%)\end{array}$ & $\begin{array}{c}\text { Observed } \\
\text { value }\end{array}$ & $\begin{array}{l}\text { RSD } \\
\text { (\%) }\end{array}$ \\
\hline Blood serum $\mu \mathrm{g} / \mathrm{dl}$ & 120 & 2.5 & 125 & 5.0 \\
\hline Urine, $\mu \mathrm{g} / \mathrm{dl}$ & 21 & 2.1 & 24 & 3.8 \\
\hline
\end{tabular}

${ }^{a}$ Three replicate analyses on a single day. ${ }^{b}$ Three replicate analyses on three different days. ${ }^{c}$ Mean $(n=3)$. ${ }^{d}$ Relative standard deviation was evaluated from three replicate analyses.

intra-day assay (three replicate measurements on a single day) and the inter-day assay (three replicate measurements on each of three days) measurements are shown for comparison. As is seen in Table 4, the RSDs of each observed value in the intra-assay measurements was below $2.5 \%$ while that in the inter-assay measurements was below $5 \%$. Thus, the present flotation preconcentration method is considered to be sufficiently precise for the quantification of zinc in human biofluids.

The analytical results for blood serum and urine samples of children with nephrotic syndrome are shown in Table 5. The mean value of total content of zinc in the serum of children with nephrotic syndrome (NS) children was lower than the mean value for healthy controls. Hypozincaemia in NS may attributed to the protein loss especially albumin (since $60-70 \%$ of zinc is carried over albumin. ${ }^{38}$ On the other hand, the mean value of the total zinc concentration in urine of NS is higher than the mean value for healthy control.

Recovery yields of zinc in natural water samples. The developed procedure for the determination of $\mathrm{Zn}$ (II) using a flotation methodology and spectrophotometry was examined

Table 6. Recovery (R, \%) of known Zn(II) concenterations added to different water samples

\begin{tabular}{lcccc}
\hline \multirow{2}{*}{ Water sample } & \multicolumn{2}{c}{$\mathrm{Zn}(\mathrm{II}) / \mu \mathrm{gL}^{-1}$} & $\begin{array}{r}\text { Recovery } \\
(\%)\end{array}$ & $\begin{array}{c}\text { RSD, } \\
\%\end{array}$ \\
\cline { 2 - 3 } & Added & Found & 102 & 2.9 \\
\hline Tap water & 0.5 & 0.51 & 103 & 3.2 \\
(Mansoura City) & 1.0 & 1.03 & 96 & 4.3 \\
Nile River & 0.5 & 0.48 & 98 & 2.4 \\
(Mansoura City) & 1.0 & 0.98 & 104 & 3.2 \\
Sea Water & 0.5 & 0.52 & 102 & 1.3 \\
(Ras El-Bar) & 1.0 & 1.02 & \\
\hline
\end{tabular}

Mean values were obtained using seven known samples

Table 5. Analytical results for total $\mathrm{Zn}(\mathrm{II})$ in human blood serum and urine samples collected from 10 healthy children and 10 cases of primary nephrotic syndrome (PNS)

\begin{tabular}{|c|c|c|c|c|c|}
\hline \multirow{2}{*}{ Sample } & \multicolumn{2}{|c|}{ Spectrophotometry } & \multicolumn{2}{|c|}{ AAS } & \multirow{2}{*}{ Sample Source $^{c}$} \\
\hline & Observed value $^{a}$ & $\operatorname{RSD}^{b}(\%)$ & Observed value & RSD (\%) & \\
\hline Blood serum, $\mu \mathrm{g} / \mathrm{dl}$ & $90[83-119.5]$ & 2.5 & 89 & 4.0 & $\mathrm{PNS}^{d}(\mathrm{M}, \mathrm{F}, 1-16 \mathrm{Y})$ \\
\hline Urine, $\mu \mathrm{g} / \mathrm{dl}$ & $42.5[30.5-62.5]$ & 3.0 & 44 & 1.5 & PNS (M,F, 1-16Y) \\
\hline Blood serum, $\mu \mathrm{g} / \mathrm{dl}$ & $124.5[95-150]$ & 4.0 & 125 & 3.0 & Healthy controls (M,F, 1-16Y) \\
\hline Urine, $\mu \mathrm{g} / \mathrm{dl}$ & $23.4[17.5-28.0]$ & 2.7 & 22.5 & 2.5 & Healthy controls (M,F, 1-16Y) \\
\hline
\end{tabular}

${ }^{a}$ Mean $(n=10)$. The values in square parathenses indicate the concentration range of blood serum and urine samples. ${ }^{b}$ Relative standard deviation. ${ }^{c}$ Samples were collected from Mansoura University Hospital of Children (Mansoura, Egypt). ${ }^{d}$ Primary Nephrotic Syndrome: a clinical state characterized by heavy proteinurea and hypoalbuminaemia; often associated with odema, hypercholesterolaemia and hyperlipidaemia. 
Table 7. Determination of $\mathrm{Zn}$ (II) in some pharmaceutical samples by the proposed flotation technique

\begin{tabular}{|c|c|c|c|c|}
\hline \multirow[b]{2}{*}{ Drug (Source) } & \multicolumn{2}{|c|}{ Spectrophotometry } & \multicolumn{2}{|c|}{ AAS } \\
\hline & $\begin{array}{l}\text { Observed } \\
\text { value }^{b}\end{array}$ & $\begin{array}{c}\mathrm{RSD}^{c} \\
(\%)\end{array}$ & $\begin{array}{l}\text { Observed } \\
\text { value }\end{array}$ & $\begin{array}{r}\text { RSD } \\
(\%)\end{array}$ \\
\hline Mineravit (E.I.P.I.Co.) & $15.2(15.0)^{a}$ & 3.0 & 14.9 & 2.9 \\
\hline $\begin{array}{l}\text { Megavit Zinc } \\
\text { (Amriya Pharm. Ind) }\end{array}$ & $24.2(23.9)$ & 2.7 & 23.7 & 3.2 \\
\hline Vitaplus Zinc (CID) & $18.3(18.2)$ & 3.6 & 18.0 & 2.9 \\
\hline
\end{tabular}

${ }^{a}$ Calculated values $(\mathrm{mg} / \mathrm{capsule}),{ }^{b}$ Mean $(\mathrm{n}=3)$, ${ }^{c}$ Relative Standard Deviation.

for several natural-water samples, Table 6. The recoveries of spiked known additions to different water samples lay within the range $96-104 \%$.

Determination of $\mathbf{Z n}$ (II) in some pharmaceutical samples. The proposed flotation procedure was successfully applied to the determination of $\mathrm{Zn}(\mathrm{II})$ in some zinc-containing drugs, Table 7, with satisfactory results.

\section{Conclusion}

In the present study zinc(II) has been enriched and separated successfully from media of diverse origin by ion flotation using PPT, as a complexing agent, prior to its spectrophotometric and AAS determination. The recommended preconcentration procedure is fast $(10 \mathrm{~min})$. The necessary equipment for flotation is simple and inexpensive. The use of a small amount of surfactant and tiny gas bubbles (vigorous shaking) necessary to perform a proper flotation cannot permit any serious contamination risks, which could be manifested by high blank volumes.

In the present investigation, the author is introducing PPT as a new reagent to the field of flotation-separation and spectrometric determination of zinc(II) in media of diverse origin. The molar absorpitivity value of the complex Zn-PPT $\left(1.83 \times 10^{5} \mathrm{~L} \mathrm{~mol}^{-1} \mathrm{~cm}^{-1}\right)$ reveals that the reagent PPT is comparable to or more sensitive for zinc(II) than some other principal reagents for zinc determination..$^{9-17}$

One of the most important advantages of the recommended method is the ability to analyze a larger volume of sample solution and to obtain a great preconcentration factor (100), as well as excellent recoveries of the trace element investigated. The effective flotation using only HOL indicates that the addition of PPT makes the sublate sufficiently hydrophobic and doesn't need two surfactants. The use of only one foaming agent needs a less amount of conc. $\mathrm{HNO}_{3}$ $(2 \mathrm{~mL})$ and makes the matrix of the final solutions tested by flame AAS less complex. A number of associated elements don't interfere with zinc(II) determination. The selectivity of the reagent is also improved by use of excess amounts of PPT and/or masking agents like thiosulfate to suppress the interference of some metal ions such as $\mathrm{Hg}$ (II), $\mathrm{Cd}$ (II) and $\mathrm{Cu}$ (II). This method has great potentiality for the successful determination of $\mathrm{Zn}$ (II) in pharmaceutical, biological and environmental samples.

\section{References}

1. Milne, D. R. Trace Elements in Tietz Textbook of Clinical Chemistry, $2^{\text {nd }}$ ed.; Saunders W. B.: Philadelphia, 1994; 1317.

2. Kim, Y. S.; Jung, Y. J.; Choi, H. S. Bull. Korean Chem. Soc. 1998, 19,50 .

3. Jan, T. K.; Young, D. R. Anal. Chem. 1978, 50, 1250.

4. Sugimae, A. Anal. Chim. Acta 1980, 121, 331.

5. Lo, J. M.; Lin, Y. P.; Lin, K. S. Anal. Sci. 1991, 7, 455.

6. Terada, K.; Inoue, A. Bull. Chem. Soc. Jpn. 1977, 50, 1060.

7. Horvath, Z.; Barnes, R. M. Anal. Chem. 1986, 58, 725.

8. Krishnamurty, K. V.; Reddy, M. M. Anal. Chim. Acta 1977, 49, 222.

9. Hiraide, M.; Yoshida, Y.; Mizuike, A. Analytica Chim. Acta 1976, $81,185$.

10. Cundeva, K.; Stafilov, T. J. Serb. Chem. Soc. 1997, 62, 523.

11. Cundeva, K.; Stafilov, T. Talanta 1997, 44, 451.

12. Ay, U.; Cundeva, K.; Akcin, G.; Stafilov, T.; Zajkova, V. P.; Pavlovska, G. Anal. Letters 2004, 37, 695.

13. Pavlovska, G.; Stafilov, T.; Cundeva, K. Fresenius J. Anal. Chem. 1998, 361, 216.

14. Huang, S.; Wu, T. P.; Ling, C. H.; Sheu, G. L.; Wu, C. C.; Cheng, M. H. J. Colloid Interface Sci. 1988, 124, 666.

15. Kim, Y.-S.; Choi, Y.-S.; Lee, W.; Lee, Y.-I. Bull. Korean Chem. Soc. 2001, 22, 821.

16. Kim, Y.-S.; Choi, Y.-S.; Lee, W. Bull. Korean Chem. Soc. 2003, 24, 1775.

17. Cundeva, K.; Stafilov, T.; Pavlovska, G. Michrochem. J. 2000, 65, 165.

18. Stafilov, T.; Zendelovska, D.; Pavlovska, G.; Cundeva, K. Spect. Chim. Acta (B) 2002, 57, 907.

19. Moustafa, G. A.; Ghazy, S. E. Anal. Sci. Jpn. 2001, 17, 1199.

20. Ghazy, S. E.; Kabil, M. A. Bull. Chem. Soc. Jpn. 1994, 76, 2098.

21. Akl, M. A.; Khalifa, M. E.; Ghazy, S. E.; Hassanein, M. M. Anal. Sci. Jpn. 2002, 18, 1235.

22. Khalifa, M. E.; Akl, M. A.; Ghazy, S. E. Chem. Pharm. Bull. Jpn. 2001, 46, 664

23. Kabil, M. A.; Akl, M. A.; Khalifa, M. E. Anal. Sci. Jpn. 1999, 15 , 433.

24. Akl, M. A.; Kabil, M. A.; Abdallaha, A. M.; Ismael, D. S. Sep. Sci. Technol. 2001, 36, 2747.

25. Kabil, M. A.; Akl, M. A.; Abdallah, A. M.; Ismael, D. S. Anal. Sci. 2000, 16, 713 .

26. Akl, M. A.; Kabil, M. A.; Abdallaha, A. M.; Ismael, D. S. Bull. Chem. Soc. Jpn. 2003, 76, 1543.

27. Abdallaha, A. M.; Kabil, M. A.; Akl, M. A.; Ismael, D. S. JICS 2004, 1, 199.

28. Akl, M. A.; Youssef, W.; Al Asmy, A. Anal. Sci. 2005, 21, 1325.

29. Akl, M. A.; Ismael, D. S.; El Asmy, A. Microchemical J. 2006, in press.

30. Mizuike, A.; Hiraide, M. Pur. Appl. Chem. 1982, 54, 1566.

31. Khalifa, M. E.; Abu El-Nadar, H. M. Revista De Chimica 1996 $47,358$.

32. Moloan, C. E. Chemical Separations: Principles, Techniques and Experiments; John Wiley \& Sons Inc.: New York, 1999; p 397.

33. Instrumental Analysis; Christianand, G. D.; O'Relly, J. E., Eds.; Alloys and Bacom, Inc.: Boston, 1986; pp 184-185.

34. Marczenko, Z. Separation and Spectrophotometric Determination of Elements; Ellis Horwood Ltd.: England, 1986; p 637.

35. Flaschka, H.; Weiss, R. Michrochemical J. 1969, 14, 318; 1970, 15,653 .

36. Goldstein, G.; Maddox, W. L.; Kelly, M. T. Anal. Chem. 1974, 46, 485.

37. Kawase, A. Talanta 1965, 12, 195.

38. Foot, J. W.; Delva, H. T. Analyst 1983, 103, 492. 